\title{
Universal Design for Learning
}

\section{Catherine A. Baldwin \\ Catherine A. Baldwin is Instruction Services Librarian at the University of Pittsburgh, Bradford Campus.}

Correspondence concerning this column should be addressed to Mark Shores; e-mail: shoresml@miamioh.edu.
Whether it is an Instruction Services Librarian revising her one-shot lesson plan or a programming librarian designing computer classes for public library clientele, universal design for learning offers a great way to create an inclusive learning environment. Arising out of the field of architecture, UDL offers a variety of teaching methods to eliminate barriers to learning and give all users, students, and patrons the chance to gain new skills. To that end, Catherine Baldwin has selected a range of books, journals and websites that should go in your library's professional development collection, and/ or for the circulating collection of your institution.-Editor

$\mathbf{T}$ he philosophy of Universal Design for Learning (UDL) has gained the attention of educators across levels and disciplines as awareness of the importance of effective, individualized learning grows. Inspired by Ron Mace's barrier-free architectural design theory of Universal Design, Universal Design for Learning is a strategy of planning curricula to accommodate the greatest number of students, regardless of their challenges and abilities. ${ }^{1}$ Just as Universal Design plans for greatest structural access and usability for all users, UDL philosophy benefits all learners, as educators facilitate learning experiences through flexibility, student choice, and often technology.

Based on neuroscience and the role of affect in learning environments, UDL philosophy rests upon three tenets: providing multiple means of engagement in material, providing multiple means of representation of material, and providing multiple means of action with and expression of material. ${ }^{2}$ Flexibility along these parameters allows for variability according to individual student needs.

Awareness of Universal Design for Learning is growing, not only within the United States, but also globally. As communication broadens and strengthens between educators within a digitally connected world, research is expanding to include studies of the application of a variety of individualized education methodologies from all regions of the world. UDL is seated among such theories and practices, applied in hopes of providing efficient, meaningful education to all learners.

When researching information regarding Universal Design for Learning, there are many offshoots branching from the topic into other areas of research. It is apparent to begin with scholarship involving the topic of education. However, due to the diverse applicability of the philosophy, related topic areas and their keywords should be considered for best results. For example, Universal Design was born of efforts to thoughtfully plan for equal access; therefore, 


\section{THE ALERT COLLECTOR}

publications regarding equal access and the related topics of special education and inclusion are starting points when researching Universal Design for Learning. Personalized Learning (PL) is connected to UDL as well, in light of both philosophies' addressing needs for individualization for each learner. Another theme bound to UDL is technology; therefore, one should consider related publications regarding new developments with assistive technology and Artificial Intelligence (AI). Universal Design for Instruction (UDI) is another related term, specifically regarding the planning of flexible, individualized educational experiences within higher education settings. Understanding by Design (UbD), Differentiated Instruction (DI), culturally responsive teaching, brain-based research, and full citizenship are other terms related to UDL. It is clear that due to the adoption of UDL by many areas within education, applying a combination of keywords (UDL, Universal Design for Learning, technology, assistive technology, learning, personalized learning (PL), education, special education, etc.) may reveal the most relevant resources.

\section{RESOURCES}

This column includes a variety of resources, including foundational materials for those establishing a preliminary knowledge of the topic of Universal Design for Learning. Practical resources are also suggested for educators and librarians who would like to quickly utilize UDL principles within a busy school or workday. Digital and print materials are suggested for accessibility and ease of use, and online resources are provided for connecting to current discussions, developments, and communities.

\section{Books}

Bracken, Seán, and Katie Novak. Transforming Higher Education through Universal Design for Learning: An International Perspective. Abingdon, Oxfordshire: Routledge, 2019 (ISBN: 9780815354727).

Including a foreword by David Rose, proponent of UDL, this text includes chapters authored by several international contributors, many of whom hold previous connections with CAST.org, the Center for Applied Special Technology. As a majority of texts focus upon pre-college students, this book addresses the instructing of young adults. Those interested in Universal Design for Instruction applications for collegeage students may gain essential information through this text.

Denning, Christopher B., and Amelia K. Moody. Inclusion and Autism Spectrum Disorder: Proactive Strategies to Support Students. New York, NY: Routledge, 2018 (ISBN: 9781138931749).

True to its suitability for all students, UDL is applied to the teaching of students diagnosed with Autism Spectrum Disorder (ASD) within this text. Chapter two is especially valuable in relation to Universal Design for Learning theory by clarifying the basis for applying UDL techniques to this specialized facet of special education. Combining theory and practical application, the authors provide information relative to teaching any student, while also specifically addressing UDL applications to benefit students with ASD.

Gronseth, Susie L., and Elizabeth M. Dalton. Universal Access through Inclusive Instructional Design: International Perspectives on UDL. Abingdon, Oxfordshire: Routledge, 2020 (ISBN: 9781138351073)

Reflecting the broadening educational community adopting UDL practices, Universal Access clarifies theory and application for students of all ages, disciplines, and abilities. Gronseth and Dalton relate foundational UDL information through an inclusive lens, considering the philosophy and principles through the perspectives of 85 countries. This text is suitable for educators of all levels and disciplines, enhancing its value as an addition to a library collection.

Hall, Tracey E., Anne Meyer and David H. Rose. Universal Design for Learning in the Classroom: Practical Applications. New York, New York: Guilford Press, 201. (ISBN: 9781462506354)

Addressing all subject areas within PreK-12 curricula, this text provides educators with theoretical bases and solutions to common learning barriers. Teaching methods, technology, and assessment are covered through succinct, quality writing. Classroom examples demonstrate related concepts, providing clarity and a solid base from which educators may develop UDL-based instruction. Low-tech applications and professional development guidelines for pre-service or experienced teachers are also included.

Meyer, Anne, David H. Rose and David Gordon. Universal Design for Learning: Theory and Practice. 1st ed., Wakefield, Massachusetts: CAST Professional Publishing, 2013 (ISBN: 9780989867405).

Foundational experts share UDL insight, research, and experiences from across educational settings in this essential text. Connection to online communities is encouraged throughout the book, extending the resources available to educators through this valuable publication.

Neimann, Theresa D., and Uta M. Stelson, eds. Challenges and Opportunities in Global Approaches to Education. Hershey, PA: IGI Global, 2019 (ISBN: 9781522597759).

Academic libraries will benefit from acquiring this text edited by Neimann and Stelson, as the topic of Universal Design for Learning is paired with Personalized Learning $(\mathrm{PL})$, which is a growing movement focusing upon the need for greater flexibility and individuation of learning strategies and experiences for each student, regardless of educational level or national origin. Challenges and Opportunities addresses rising global awareness and adoption of UDL strategies, not only as practice, but oftentimes as legal policy. 
"Section 3: Global Challenges and Opportunities in Increasing Student Competencies" offers perspectives and policies from various corners of the globe, illustrating a growing consensus for applying UDL as a best practice within various fields of education.

Nelson, Loui L. Design and Deliver: Planning and Teaching Using Universal Design for Learning. Baltimore: Brookes Publishing, 2013. Illustrated by Allison Posey (ISBN: 9781598573503).

Nelson offers a detailed overview within a digestible format, including metaphorical examples of concepts and practical classroom applications in regard to relevant educational issues, including Common Core guidelines, assessment, lesson planning, and trouble shooting. The author adopts a comprehensive view of the field of teaching, including information on what, how, and why to plan lessons utilizing UDL, by efficiently filling in background information for novice educators while providing clarity for those with more experience. In addition, the author provides real world examples and classroom connections via teacher anecdotes, tables comparing teaching strategies, and references to chapters within the book for additional information. Instructors teaching any level or subject would benefit from this book, lending to its high value as an acquisition.

Rapp, Whitney H., Katrina L. Arndt, and Susan M. Hildenbrand. Picture Inclusion!: Snapshots of Successful Diverse Classrooms. Baltimore, MD: Paul H. Brookes Publishing, 2019 (ISBN: 9781681252933)

Rapp, et al., analyze four tenets of the inclusive classroom, including Universal Design for Learning, Response to Intervention (RTI), clustering, and embedded instruction methods (p. 597f). The authors' incorporation of UDL with other strategies demonstrates the flexibility of UDL application across student learner populations, regardless of the presence or absence of learning challenges. However, the text aptly demonstrates the special value of applying UDL strategies to the development of an inclusive classroom.

Rapp, Whitney H. Universal Design for Learning in Action: 100 Ways to Teach all Learners. Baltimore, Maryland: Paul H. Brookes Publishing, 2014 (ISBN: 9781598573909)

Rapp provides a thorough overview of foundational educational theories, including universal design for learning (UDL), understanding by design (UbD), differentiated instruction (DI), culturally responsive teaching, brain-based research, and full citizenship, thereby illustrating the interconnectedness of these prominent theories. The author also clarifies why UDL should be the base of curriculum planning for students, from early childhood through emerging adulthood. Rapp lists suggested books and other resources for further reading on each topic, and the structure of the book itself outlines the main tenets of UDL, with large sections on the means of representation, means of expression, and means of assessment of learning forming the majority of the text, thereby providing real world applications of the theories.
Rose, David A., and Anne Meyer. A Practical Reader in Universal Design for Learning. Cambridge, MA: Harvard Education Press, 2006 (ISBN: 978891792298).

Through this collection of articles and lessons, Rose and Meyer offer classroom applications and solutions for applying UDL principles to teaching pre-college students. It should be noted that any collection of resources regarding UDL will include several publications written or edited by Rose and Meyer.

\section{Journals}

With rising awareness of UDL, there exists an expanding number of quality resources addressing the application of UDL principles throughout learning levels and disciplines. Articles addressing Universal Design for Learning are plentiful, however, they tend to be published across a variety of journals and specialty areas, with articles addressing specific applications of UDL for a particular niche. Conversely, journals committed singularly to UDL are challenging to identify.

Journal of Learning Design (www.jld.edu.au/)

One dedicated resource of note is the open access Journal of Learning Design, which addresses pedagogical topics related to UDL. The journal is available online and offers articles through 2017.

Journal of Special Education Technology (https://journals.sage pub.com/home/jst)

Part of the family of SAGE journals, the Journal of Special Education Technology (JSET) addresses the application of technology within this specialized, yet universal, subset of education. Because UDL principles often employ assistive technology, this journal addresses UDL topics.

\section{Websites}

Center for Applied Special Technology (www.CAST.org)

The Center for Applied Special Technology is a nonprofit organization dedicated to education research and Universal Design for Learning principles. Founded and supported by preeminent UDL theorists, CAST is a prominent source of UDL information for a wide array of users. Under the "What's New: Learning Tools" tab (www.cast.org/whats-new/learn ing-tools.html) are several free digital resources and tools for families, educators, and librarians concerned with providing access. "UDL Editions" is one such resource which includes "classic texts from world literature in a flexible online interface with ... supports for struggling and expert readers alike." The "UDL Book Builder" is another resource located within the web page of "Learning Tools," which provides a platform for creating digital books. Also included is the CAST UDL Exchange (http://udlexchange.cast.org/home), a website that combines elements of social media with a traditional site format, enabling educators to utilize and refine the site's 


\section{THE ALERT COLLECTOR}

existing lesson plans, to create new lessons, and to also share lessons in the spirit of open access.

National Center on Accessible Educational Materials (https:// aem.cast.org)

The NCEAM provides resources and technical assistance for educators, parents, students, publishers, conversion houses, accessible media producers, and others, in to provide online tools for learners with disabilities. One of the NCEAM's initiatives is PALM (Purchase Accessible Learning Materials) (https://aem.cast.org/navigating/palm.html), created to encourage educators to increase the demand for educational materials of enhanced accessibility. This site may be useful for librarians, as it contains information pertaining to accessible materials and related professional communities.

UDL Center: Medium.com (https://medium.com/udl-center)

Medium.com is a website offering free access to articles on timely issues and topics, with affordable subscription membership unlocking greater access. The site provides thoughtful and varied perspectives on a wide array of topic areas, including education and UDL in particular. Medium hosts the UDL Center site, which is an updated product of the National Center on Universal Design for Learning at CAST.org. This site provides the UDL Guidelines within a clear graphic organizer which includes live links to examples and clarifications of concepts. It also offers links to "checkpoints," or outcomes, for assessing the application of the guidelines. The guidelines page contains a wealth of information on UDL as well as ideas for application at any learning level within any learning environment.

\section{References}

1. Tracy Hall, Anne Meyer, and David Rose, "An Introduction to Universal Design for Learning: Questions and Answers," in Universal Design for Learning in the Classroom: Practical Applications, (New York: Guilford Press, 2012), 1-8.

2. Scott Lapinski, Jenna Gravel, and David Rose, "Tools for Practice: The Universal Design for Learning Guidelines," in Universal Design for Learning in the Classroom: Practical Applications (New York: Guilford Press, 2012), 9-24. 